\title{
The Effect of Body Mass Index on Oncological and Surgical Outcomes in Patients Undergoing Radical Cystectomy for Bladder Cancer: A Multicenter Study of the Association of Urooncology, Turkey
}

\author{
Volkan Izol ${ }^{1}$, Mutlu Deger ${ }^{1}$, Sumer Baltaci ${ }^{2}$, Murat Akgul $^{3}$, İsmail Selvi ${ }^{4}$, Ender Ozden ${ }^{5}$, \\ Evren Suer ${ }^{2}$, and Mustafa Tansug ${ }^{1}$ \\ ${ }^{1}$ Cukurova University Faculty of Medicine \\ ${ }^{2}$ Ankara University Faculty of Medicine \\ ${ }^{3}$ Namik Kemal University Faculty of Medicine \\ ${ }^{4}$ Ankara Kecioren Training and Research Hospital \\ ${ }^{5}$ Ondokuz Mayis University Faculty of Medicine
}

August 28, 2020

\begin{abstract}
Objective: We aimed to evaluate the effect of body mass index (BMI) on oncological and surgical outcomes in patients who underwent radical cystectomy (RC) for bladder cancer (BC). Materials and Methods We retrospectively assessed data from patients who underwent $\mathrm{RC}$ with pelvic lymphadenectomy and urinary diversion for $\mathrm{BC}$ recorded in the bladder cancer database of the Urooncology Association, Turkey between 2007 and 2019. Patients were stratified into three groups according to the BMI cut-off values recommended by the WHO; Group 1 (normal weight, $<25 \mathrm{~kg} / \mathrm{m} 2$ ), Group 2 (overweight, 25.0-29.9 kg/m2) and Group 3 (obese, [?]30 kg/m2) Results In all, 494 patients were included, of them $429(86.8 \%)$ were male and 65 (13.2\%) were female. The median follow-up was 24 months (12-132 months). At the time of surgery, the number of patients in groups 1, 2 and 3 were 202 (40.9\%), 215 (43.5\%) and 77 (15.6\%), respectively. The mean operation time and time to postoperative oral feeding were longer and major complications were statistically higher in Group 3 compared to Groups 1 and 2 ( $\mathrm{p}=0.019, \mathrm{p}<0.001$ and $\mathrm{p}=0.025$ respectively). Although the mean overall survival (OS), cancer-specific survival (CSS), recurrence-free survival (RFS) and metastasis-free survival (MFS) was shorter in cases with BMI [?]30 kg/m2 compared with other BMI groups, differences were not statistically significant $(\mathrm{p}=0.532, \mathrm{p}=0.309, \mathrm{p}=0.751$ and $\mathrm{p}=0.213$ respectively). Conclusion Our study showed that, although major complications are more common in obese patients, the increase in BMI does not reveal a significant negative effect on OS, CSS, RFS, and MFS.
\end{abstract}

\section{Materials and Methods}

We retrospectively assessed data from patients who underwent $\mathrm{RC}$ with pelvic lymphadenectomy and urinary diversion for $\mathrm{BC}$ recorded in the bladder cancer database of the Urooncology Association, Turkey between 2007 and 2019. Patients were stratified into three groups according to the BMI cut-off values recommended by the WHO; Group 1 (normal weight, $<25 \mathrm{~kg} / \mathrm{m}^{2}$ ), Group 2 (overweight, 25.0-29.9 $\mathrm{kg} / \mathrm{m}^{2}$ ) and Group 3 (obese, [?]30 kg/m²)

\section{Results}

In all, 494 patients were included, of them $429(86.8 \%)$ were male and $65(13.2 \%)$ were female. The median 
follow-up was 24 months (12-132 months). At the time of surgery, the number of patients in groups 1,2 and 3 were $202(40.9 \%), 215(43.5 \%)$ and $77(15.6 \%)$, respectively. The mean operation time and time to postoperative oral feeding were longer and major complications were statistically higher in Group 3 compared to Groups 1 and 2 ( $\mathrm{p}=0.019, \mathrm{p}<0.001$ and $\mathrm{p}=0.025$ respectively).

Although the mean overall survival (OS), cancer-specific survival (CSS), recurrence-free survival (RFS) and metastasis-free survival (MFS) was shorter in cases with BMI [?]30 kg/m² compared with other BMI groups, differences were not statistically significant $(\mathrm{p}=0.532, \mathrm{p}=0.309, \mathrm{p}=0.751$ and $\mathrm{p}=0.213$ respectively).

\section{Conclusion}

Our study showed that, although major complications are more common in obese patients, the increase in BMI does not reveal a significant negative effect on OS, CSS, RFS, and MFS.

Keywords: Bladder cancer, radical cystectomy, body mass index, obesity

\section{Introduction}

Bladder cancer $(\mathrm{BC})$ is the eleventh most diagnosed cancer in both sexes. The worldwide age-standardized incidence rate is 9.0 cases per 100,000 per year for men and 2.2 for women ${ }^{1}$. Approximately $75 \%$ of patients diagnosed with $\mathrm{BC}$ have mucosal disease and $15-25 \%$ have muscle invasive $\mathrm{BC}^{2}$. EAU Guidelines report that radical cystectomy $(\mathrm{RC})$ is the standard treatment for localized MIBC and suggests for non-invasive tumors with the highest risk of progression ${ }^{1}$.

Complications related to RC may be directly related to surgery, intestinal anastomosis or urinary diversion, other than previously existing comorbidity ${ }^{3}$. Early complications such as perioperative blood transfusion and gastrointestinal complications occur in $55-78 \%$ and major complications in $32 \%$ of the patients ${ }^{4}$. Late complications include urinary tract infection, kidney dysfunction, stone formation, metabolic complications, and relapse of the disease. Peri-operative mortality for RC and urinary diversion was reported as 2.3-8.0\% at 90 days ${ }^{1}$. Increased BMI, High American Society of Anesthesiologists (ASA) score, bleeding, and Charlson Comorbidity Index (CCI) are among the known causes of perioperative complications ${ }^{5}$. Patients undergoing $\mathrm{RC}$ for $\mathrm{BC}$, the 5 -year recurrence-free survival (RFS) rate was $58 \%$, cancer-specific survival (CSS) was $66 \%$ and overall survival (OS) was $66 \%{ }^{6,7}$. Some of the most significant predictors of OS of RC with urinary diversion are age, ASA, smoking habits, stage, grade, nodal status, neoadjuvant chemotherapy, general condition status and delay from the first symptoms to surgery ${ }^{8}$.

The effect of body mass index (BMI) on oncological and surgical outcomes of RC with urinary diversion is controversial. A number of studies examining the role of BMI in patients with BC report that high BMI is associated with a high risk of $\mathrm{BC}$ development and disease recurrence, negatively affecting cancer-specific mortality and surgical morbidity ${ }^{2,9,10}$. However, conflicting findings have also been reported which showed that BMI does not affect disease-specific survival after RC, and the complication, transfusion rates, and length of hospital stay are similar ${ }^{11-14}$. In this multicenter study, we tried to evaluate the effect of increased $\mathrm{BMI}$ on surgical and oncological outcomes of $\mathrm{BC}$ patients treated with $\mathrm{RC}$, using the $\mathrm{BC}$ database of the Urooncology Association, Turkey

\section{Materials and Methods}

\section{Patient selection}

We retrospectively assessed data from patients who underwent $\mathrm{RC}$ with pelvic lymphadenectomy and urinary diversion for $\mathrm{BC}$ recorded in the $\mathrm{BC}$ database of the Urooncology Association, Turkey between 2007 and 2019. All procedures were performed by 8 experienced surgeons from six different institutions. RC with pelvic lymphadenectomy and urinary diversion was performed for localized MIBC or non-muscle-invasive tumors who \soutare were at highest risk of progression. The extensiveness of pelvic lymphadenectomy and the type of urinary diversion was at surgeons' discretion. Patients with concurrent presence of upper urinary tract carcinoma or/and the history of cancer other than bladder cancer or/and patients underwent robotic assisted $\mathrm{RC}$ due to low number or/and missing variables were excluded. 


\section{Data Collection}

Patients were stratified into three groups according to WHO guidelines; Group 1 (normal weight, $<25$

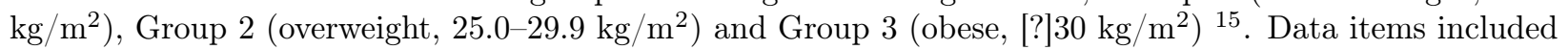
demographic characteristics such as age, gender, presence of diabetes, coronary artery disease, hypertension, ASA score, ECOG performance status score, operative data including surgical approach, type of diversion and lymph node dissection were recorded and analyzed. The complications were classified according to the modified Clavien system and were retrospectively analyzed ${ }^{16}$. Pathological specimens were evaluated at each institution's pathology department using Tumor Node Metastasis classification for staging and the 2004 World Health Organization classification for grading. Ethics committee approval for the study was obtained from the ethics committee of the University of Çukurova (approval number- September 4,2019;91/60).

\section{Follow up}

Similar follow-up protocol was used at each center. The patients were seen initially 1 month after surgery, then every 3 months for the first year, every 6 months for the second year and annually thereafter. The follow-up visits consisted of a physical examination and laboratory studies. Imaging modalities including chest radiography, abdominal CT or ultrasonography were applied at least every 6 months or when clinically indicated.

The primary outcome measures in this study were overall survival (OS), cancer-specific survival (CSS), recurrence-free survival (RFS), metastasis-free survival (MFS) and disease free survival (DFS). Duration of follow-up was the time from surgery to the date of death or last clinic visit.

\section{Statistical Analysis}

All analyzes were done with IBM SPSS Statistics Version 20.0 statistical software package. Categorical variables were expressed as numbers and percentages, while continuous variables were summarized as mean and standard deviation as well as median and minimum-maximum if necessary. The chi-square test was used to compare categorical variables between the groups. For non-normal distributed data, Kruskal Wallis test was used to compare more than two groups. For univariate analysis event free survival was calculated by Kaplan-Meier method and log rank test was performed. Cox regression analysis was performed to determine significant predictors of OS and CSS variable. In univariate analysis, variables significant at the $\mathrm{P}<0.1$ level were entered in Cox regression analysis. The statistical level of significance for all tests was considered to be 0.05 .

\section{Results}

A total of 494 patients were eligible for final analyses, of them 429 (86.8\%) were male and $65(13.2 \%)$ were female. The mean age of the patients was $64.3 \pm 9.2$ years (range 59.0-70.0 years).

The open RC $419(85.3 \%)$ was performed more frequently compared with laparoscopic approach $72(14.7 \%)$ ( $\mathrm{p}=0.008)$. The median follow-up time was 24 months (12-132 months).

Among 494 patients, 202 (40.9\%) had normal BMI (Group 1), 215 (43.5\%) were over-weighted (Group 2) and $77(15.6 \%)$ were obese (Group 3) at the time of surgery. Demographic and clinical characteristics of these groups are presented in Table 1 . These BMI groups were similar in terms of characteristics in Table 1, except gender and ECOG performance status ( $\mathrm{p}=0.002$ and $\mathrm{p}<0.001$ respectively). We found that ECOG performance status 0 and 1 was statistically significantly higher in Group 1 and Group 3, respectively $(\mathrm{p}=<0.001)$

\section{Operative Outcomes}

Operative characteristics of the patients are listed in Table 2. There were no statistically significant differences in urinary diversion type, drain and nasogastric tube withdrawal time, intestinal motility, mobilization and length of stay between the groups. Open RC was performed in $419(84.8 \%)$ patients and $75(15.2 \%)$ patients underwent laparoscopic $\mathrm{RC}(\mathrm{p}=0.008)$. The mean operative time was $317.1 \pm 92.1,339.2 \pm 112.1$, and 
$360.6 \pm 120.2$, in Group 1, 2 and 3, respectively. Among the groups, more convenient inferences were obtained in Group 3, including longer operation time and oral feeding start $(\mathrm{p}=0.019, \mathrm{p}<0.001)$. Patients' readmission to hospital within 30 and 90 days of surgery were $13.2 \%$ and $16.2 \%$, respectively, and there was no difference between the groups $(\mathrm{p}=0.710$, and $\mathrm{p}=0.275$ respectively). The mean number of removed lymph nodes was $19.5 \pm 14.9,20.1 \pm 12.8$ and $19.3 \pm 10.4$ in Group 1, 2 and 3, respectively. There was no difference between the 3 groups in terms of lymph node positivity $(\mathrm{p}=0.210)$. Groups were also similar in terms of surgical margin positivity $(\mathrm{p}=078)$.

Perioperative complication was seen in 17(8.4\%), 4(1.9\%) and 5(6.5\%) patients in Group 1, 2 and 3, respectively and Group 2 had significantly fewer complication rate $\backslash$ souts compared with Group 1 and 3 ( $\mathrm{p}=0.01$ ). Statistically significant major complication rate was observed in Group 3 compared to Group 1 and 2 $(\mathrm{p}=\mathbf{0 . 0 2 5})$. There was no significant difference between groups in terms of transfusion (perioperative, postoperative) and readmission rates (30-day, 90-day) (Table 3 ). All of the pathological characteristics of the patients were found to be similar among the groups (Table 4 ).

\section{Survival Outcome}

Although the mean OS and CSS was shorter in cases with BMI $>29.9 \mathrm{~kg} / \mathrm{m} 2$ compared with other BMI groups (74.2 vs. 84.4 and 94.2 months for OS, 97.5 vs. 105.1 and 101.0 months for CSS, respectively), the differences were not statistically significant $(\mathrm{p}=0.532$ and $\mathrm{p}=0.309$, respectively) (Figure 1). A Cox proportional hazards model was used to evaluate the potential predictors for OS and CSS and the results are shown in Table $\mathbf{5}$. Analysis revealed that OS and CSS was significantly associated with "Lymphovascular invasion" (HR: 2.17, 95\% CI: (1.30-3.60); $\mathrm{p}=0.003$ (OS), HR: 2.55, 95\% CI: (1.30-4.98); $\mathrm{p}=0.006$ (CSS) ). In multivariate analysis, "pN+: N2" (HR: 4.80, 95\% CI: (2.79-8.24); p<0.001 (OS), HR: 4.11, 95\% CI: (1.908.90); $\mathrm{p}<0.001$ (CSS)) was found to be the independent prognostic factor for OS and CSS. The association between increased BMI and mortality was not statistically significant in analysis $(\mathrm{p}>0.05)$. Although the mean RFS and MFS was shorter in cases with BMI $>29.9 \mathrm{~kg} / \mathrm{m} 2$ compared with other BMI groups, there was no statistically significant difference between BMI groups in terms of RFS and MFS ( $p=0.751$ and $p=0.213$ respectively)

\section{(Figure 2).}

\section{Discussion}

The prevalence of being overweight or obese has increased by $27.5 \%$ for adults, and obesity continues to be a major health problem worldwide ${ }^{17}$. The risk for multiple medical problems that can adversely affect surgical outcomes is increased in obese patients ${ }^{18}$. The relationship of BMI with bladder cancer and radical cystectomy has been the subject of scientific research in the past decade. However, in the literature, the results regarding the effect of obesity on the surgical and oncological outcomes of patients after RC for BC are still contradictory ${ }^{2,9-12}$. In this study, we evaluated the effect of BMI on oncologic and surgical outcomes in patients who underwent radical $\mathrm{RC}$ for $\mathrm{BC}$. We found that the operation time and oral feeding start were longer and major complications were more common in obese patients. The results revealed that the mean OS, CSS, RFS, and MFS was shorter in cases with BMI $>29.9 \mathrm{~kg} / \mathrm{m} 2$ compared with other BMI groups, however, the differences were not statistically significant.

Due to greater technical challenges, many studies reported that increased BMI is independently associated with perioperative and postoperative risks after RC. In a study on 1293 patients who underwent radical cystectomy, Tyson MD et al., by comparing patients with $\mathrm{BMI}<30$ and patients with BMI [?]30, found that obese patients had longer operation time and more renal failure and \soutthey noted no differences in 30-day mortality after $\mathrm{RC}{ }^{19}$. In another study, Maurer $\backslash$ soutand $\mathrm{T}$ et al, by comparing normal weight, and overweight patients who underwent RC, revealed that there was no significant difference according to intraoperative blood transfusion rate, postoperative TNM stage, and postoperative complications. They noted that the time of surgery was significantly prolonged and postoperative bleeding was more common in overweight patients ${ }^{13}$. After analyzing the data of 671 patients who underwent radical cystectomy, Gierth $\mathrm{M}$ et al reported that, there was no significant relationship between obesity and tumor stage, grade, lymph 
node metastasis, blood loss, urinary diversion type, and 90-day mortality. Severe complications within 30 days after RC, blood transfusion rates were higher and the mean operation time was longer in patients with BMI [?]30 kg/m² compared to the other BMI groups ${ }^{20}$. Another study by Lee et al showed that number of complications is higher in obese patients, but complication severity was similar between BMI groups ${ }^{21}$. In our study, statistically significant major complication rate was observed in Group 3 compared to Group 1 and $2(\mathrm{p}=\mathbf{0 . 0 2 5})$.

Increased BMI is associated with risk for many cancers, including urological cancers. It is also thought that cancer is associated with poor prognoses ${ }^{22-24}$. Many studies $\backslash$ soutevaluating examined the relationship between obesity and oncological outcomes of $\mathrm{RC}^{2,11,12,20,25}$. In multivariable analysis of $4118 \mathrm{RC}$ patients due to BC, Chromecki et al found that patients with BMI> 30 had higher disease recurrence (HR 1.67, 95\% CI $1.46-1.91, \mathrm{P}<0.001$ ), lower CSS (HR 1.43, 95\% CI 1.24-1.66, P < 0.001), and lower OS (HR 1.81, CI $1.60-2.05, \mathrm{P}<0.001)$. They thought that, this finding might be related to the metabolic syndrome seen in obese patients ${ }^{25}$. In another study, Dabi et al. found that the risk of disease recurrence or cancer-specific mortality increased by 1.5 fold for obese patients. They reported that increased BMI is an independent prognostic factor for oncological results of $\mathrm{BC}$ patients who underwent $\mathrm{RC}{ }^{2}$. In literature, conflicting findings have also been reported. In a retrospective study, which analyzed the data of 300 patients who underwent cystectomy (radical or partial) due to BC and whose median follow-up was 39 months, Hafron $\mathrm{J}$ et al showed that the increase in BMI has no effect on OS or disease-specific survival in univariate or multivariate analysis. In addition, they found that age over 65 years, tumor stage, smoking, and the positive tissue margin were significant factors affecting OS ${ }^{11}$. Also, Gierth et al. found that increased BMI had no effect on survival and not associated with more aggressive tumor biology ${ }^{20}$. On the other hand, Kwon et al reported that overweight and obesity were associated with favorable pathological features and prognosis in patients with bladder cancer undergoing radical cystectomy [12]. Our study showed that the increase in BMI does not have a statistically significant negative effect on DSS and OS

The surgical approach is another point of discussion. The guidelines have recommended that none of the surgical approaches (open-, laparoscopic- or robotic RC) has clearly shown superiority in terms of functional or oncological results. In the CORAL study, a prospective study by Khan et al, the authors found no difference in 5-yr RFS, CSS, and OS rates of patients who underwent open, laparoscopic and robotic radical cystectomy for management of bladder cancer. Minimally invasive techniques achieved equivalent oncological outcomes to the gold standard of ORC ${ }^{26}$. After analyzing robot-assisted radical cystectomy (RARC) cases, Butt et al found that, overweight and obese patients had similar complication rates, operative times and estimated blood loss compared with patients with normal BMI ${ }^{27}$. Ahmadi et al showed that, BMI was not associated with significant differences in peri-operative, pathological or early oncological outcomes in patients undergoing RARC ${ }^{28}$. In our study, we did not include the RARC cases, as the number of those patients was very low. We found no statistically significant effect of surgical approach (open or laporoscopic) in terms of OS and CSS.

The present study has some limitations. Data collection and analysis was retrospective and non-randomized. Therefore, unidentified confounding variables may have an effect on the results. Another limitation was the performance of procedures by 8 high-volume surgeons in 6 different centers. However, this limitation is always present in such multicenter studies. Moreover, lack of central pathologic assessment is also a limitation.

\section{Conclusion}

We conclude that, although major complications are more common in obese patients, the increase in BMI does not reveal a significant negative effect on OS, CSS, RFS and MFS.

Across the spe ctrum of obese patients undergoing RARC with intracorporeal diversion, quality of surgery, postoperative data, pathological outcomes, complications and readmission rates were similar. Early oncological outcomes were also similar amongst patients in all four BMI categories. We conclude that, given an experienced robot-assisted surgery team, RARC with intracorporeal diversion is an effective option for overweight, obese and morbidly obese patients with bladder cancer who are considering RC. Across the spectrum 
of obese patients undergoing RARC with intracorporeal diversion, quality of surgery, postoperative data, pathological outcomes, complicationsand readmission rates were similar. Early oncological outcomes were also similar amongst patients in all four BMI categories. We conclude that, given an experienced robotassisted surgery team, RARC with intracorporeal diversion is an effective option for overweight, obese and morbidly obese patients with bladder cancer who are considering RC.

\section{ACKNOWLEDGEMENTS}

Ethics committee approval of the study was obtained from the ethics committee of the University of Cukurova (approval number-April 5,2019;87/54).

\section{CONFLICTS OF INTEREST}

The authors report no conflicts of interest.

\section{REFERENCES}

1. Witjes JA, Bruins HM, Cathomas R, et al. European Association of Urology Guidelines on Muscle-invasive and Metastatic Bladder Cancer: Summary of the 2020 Guidelines. Eur Urol. 2020.

2. Dabi Y, Rouscoff Y, Anract J, et al. Impact of body mass index on the oncological outcomes of patients treated with radical cystectomy for muscle-invasive bladder cancer. World journal of urology.2017;35(2):229235.

3. Hautmann RE, Abol-Enein H, Davidsson T, et al. ICUD-EAU international consultation on bladder cancer 2012: urinary diversion. European urology. 2013;63(1):67-80.

4. Oedorf K, Skaaheim Haug E, Liedberg F, et al. Perioperative management of radical cystectomy in the Nordic countries.Scandinavian journal of urology. 2019;53(1):51-55.

5. Lee CU, Kang M, Kim TJ, et al. Predictors of postoperative complications after robot-assisted radical cystectomy with extracorporeal urinary diversion. Cancer Management and Research.2019;11:5055.

6. Nuhn P, May M, Sun M, et al. External validation of postoperative nomograms for prediction of all-cause mortality, cancer-specific mortality, and recurrence in patients with urothelial carcinoma of the bladder. European urology. 2012;61(1):58-64.

7. Stein JP, Lieskovsky G, Cote R, et al. Radical cystectomy in the treatment of invasive bladder cancer: long-term results in 1,054 patients. Journal of clinical oncology. 2001;19(3):666-675.

8. Kwiatkowska M, Dybowski B, Kuczkiewicz-Siemion O, et al. Factors affecting one-year survival after radical cystectomy: A prospective study. Central European Journal of Urology. 2017;70(3):238.

9. Abern MR, Freedland SJ, Inman BA. Obesity is associated with worse oncological outcomes in patients treated with radical cystectomy.BJU international. 2013;111(2):187-188.

10. Wolk A, Gridley G, Svensson M, et al. A prospective study of obesity and cancer risk (Sweden). Cancer causes $\& 3$ control.2001;12(1):13-21.

11. Hafron J, Mitra N, Dalbagni G, Bochner B, Herr H, Donat SM. Does body mass index affect survival of patients undergoing radical or partial cystectomy for bladder cancer? The Journal of urology.2005;173(5):1513-1517.

12. Kwon T, Jeong IG, You D, et al. Obesity and prognosis in muscle-invasive bladder cancer: The continuing controversy.International Journal of Urology. 2014;21(11):1106-1112.

13. Maurer T, Maurer J, Retz M, et al. Influence of body mass index on operability, morbidity and disease outcome following radical cystectomy. Urologia internationalis. 2009;82(4):432-439. 
14. Teleka S, Haggstrom C, Nagel G, et al. Risk of bladder cancer by disease severity in relation to metabolic factors and smoking: a prospective pooled cohort study of 800,000 men and women. International journal of cancer. 2018;143(12):3071-3082.

15. Obesity: preventing and managing the global epidemic. Report of a WHO consultation. World Health Organ Tech Rep Ser.2000;894:i-xii, 1-253.

16. Dindo D, Demartines N, Clavien P-A. Classification of surgical complications: a new proposal with evaluation in a cohort of 6336 patients and results of a survey. Annals of surgery.2004;240(2):205.

17. Ng M, Fleming T, Robinson M, et al. Global, regional, and national prevalence of overweight and obesity in children and adults during 1980-2013: a systematic analysis for the Global Burden of Disease Study 2013. Lancet. 2014;384(9945):766-781.

18. Haffner SM, Valdez RA, Hazuda HP, Mitchell BD, Morales PA, Stern MP. Prospective analysis of the insulin-resistance syndrome (syndrome X).Diabetes. 1992;41(6):715-722.

19. Tyson MD, Humphreys MR, Castle EP. Obese patients undergoing cystectomy: a population-based, propensity score matched analysis. Int $J$ Urol. 2014;21(5):491-495.

20. Gierth M, Zeman F, Denzinger S, et al. Influence of Body Mass Index on Clinical Outcome Parameters, Complication Rate and Survival after Radical Cystectomy: Evidence from a Prospective European Multicentre Study. Urol Int. 2018;101(1):16-24.

21. Lee CT, Dunn RL, Chen BT, Joshi DP, Sheffield J, Montie JE. Impact of body mass index on radical cystectomy. J Urol. 2004;172(4 Pt 1):1281-1285.

22. Cao Y, Ma J. Body mass index, prostate cancer-specific mortality, and biochemical recurrence: a systematic review and meta-analysis. Cancer Prev Res (Phila). 2011;4(4):486-501.

23. Chan DS, Vieira AR, Aune D, et al. Body mass index and survival in women with breast cancersystematic literature review and meta-analysis of 82 follow-up studies. Ann Oncol. 2014;25(10):1901-1914.

24. Schlesinger S, Siegert S, Koch M, et al. Postdiagnosis body mass index and risk of mortality in colorectal cancer survivors: a prospective study and meta-analysis. Cancer Causes Control.2014;25(10):1407-1418.

25. Chromecki TF, Cha EK, Fajkovic H, et al. Obesity is associated with worse oncological outcomes in patients treated with radical cystectomy. BJU Int. 2013;111(2):249-255.

26. Khan MS, Omar K, Ahmed K, et al. Long-term Oncological Outcomes from an Early Phase Randomised Controlled Three-arm Trial of Open, Robotic, and Laparoscopic Radical Cystectomy (CORAL). Eur Urol.2020;77(1):110-118.

27. Butt ZM, Perlmutter AE, Piacente PM, et al. Impact of body mass index on robot-assisted radical cystectomy. Jsls.2008;12(3):241-245.

28. Ahmadi N, Clifford TG, Miranda G, et al. Impact of body mass index on robot-assisted radical cystectomy with intracorporeal urinary diversion. BJU Int. 2017;120(5):689-694.

\section{Hosted file}

Table 1.docx available at https://authorea.com/users/353511/articles/477353-the-effect-ofbody-mass-index-on-oncological-and-surgical-outcomes-in-patients-undergoing-radicalcystectomy-for-bladder-cancer-a-multicenter-study-of-the-association-of-urooncologyturkey

\section{Hosted file}

Table 2.docx available at https://authorea.com/users/353511/articles/477353-the-effect-ofbody-mass-index-on-oncological-and-surgical-outcomes-in-patients-undergoing-radical- 
cystectomy-for-bladder-cancer-a-multicenter-study-of-the-association-of-urooncologyturkey

\section{Hosted file}

Table 3.docx available at https://authorea.com/users/353511/articles/477353-the-effect-ofbody-mass-index-on-oncological-and-surgical-outcomes-in-patients-undergoing-radicalcystectomy-for-bladder-cancer-a-multicenter-study-of-the-association-of-urooncologyturkey

\section{Hosted file}

Table 4.docx available at https://authorea.com/users/353511/articles/477353-the-effect-ofbody-mass-index-on-oncological-and-surgical-outcomes-in-patients-undergoing-radicalcystectomy-for-bladder-cancer-a-multicenter-study-of-the-association-of-urooncologyturkey

\section{Hosted file}

Table 5.docx available at https://authorea.com/users/353511/articles/477353-the-effect-ofbody-mass-index-on-oncological-and-surgical-outcomes-in-patients-undergoing-radicalcystectomy-for-bladder-cancer-a-multicenter-study-of-the-association-of-urooncologyturkey

\section{Hosted file}

Figure 1.docx available at https://authorea.com/users/353511/articles/477353-the-effectof-body-mass-index-on-oncological-and-surgical-outcomes-in-patients-undergoing-radicalcystectomy-for-bladder-cancer-a-multicenter-study-of-the-association-of-urooncologyturkey

\section{Hosted file}

Figure 2.docx available at https://authorea.com/users/353511/articles/477353-the-effectof-body-mass-index-on-oncological-and-surgical-outcomes-in-patients-undergoing-radicalcystectomy-for-bladder-cancer-a-multicenter-study-of-the-association-of-urooncologyturkey 